analytical methods in general and quality control are outstanding and the summaries of the chemical processes which underlie commonly performed tests provide just enough information for the intelligent non-chemist to understand and evaluate them. In short, this is a book that can be thoroughly and confidently recommended to any intelligent clinician as well as to chemical pathologists; and hospital working libraries could do no better than invest in a copy.

\section{Tenth Symposium on Advanced Medicine}

Edited by J. G. G. Ledingham. Pp. xii +475 , illustrated. London: Pitman Medical, 1974. $£ 6.00$ (paperback).

The annual symposia in Advanced Medicine at the Royal College of Physicians are a welcome and enjoyable part of the winter season of postgraduate medical education. The subsequent publications remain a permanent source of instruction, and the standard of these books is never other than high. This record of the Tenth Symposium held in February 1974 is no exception and has particular merits. The major one, to the reviewer's mind, is the broad spectrum of its subject matter under nine sessional headings including medical problems in pregnancy, endocrine and metabolic disorders, neurology, haematology, renal disease, infectious disease and cardiorespiratory medicine. The specific subjects covered under each heading have been chosen to review present knowledge and titillate the appetite for learning more in currently important and advancing fields. Another session covered the HLA system and disease, immunology and the gut, renin, cholera and its fascinating metabolic implications. These 'Incomplete Stories' are acknowledged to be no less complete than most of the others.

A great book with bang up-to-date references. A profitable investment for the individual and institutions. 